\title{
Synthesis of Stereoregular Polysaccharide Derivatives Carrying 2,3-Di-O-alkyl Chains
}

\author{
Ken-Ichi Kanno, Wataru Kinoshita, Kazukiyo Kobayashi, ${ }^{*}$ \\ and Kenichi HatanaKa ${ }^{\dagger}$ \\ Department of Biomolecular Engineering, Tokyo Institute of Technology, \\ 4259 Nagatsuta-cho, Midori-ku, Yokohama 226, Japan \\ * Faculty of Agriculture, Nagoya University, \\ Chikusa-ku, Nagoya 464-01, Japan
}

(Received February 23, 1995)

\begin{abstract}
A new 1,6-anhydro-sugar monomer carrying 2,3-di- $O$-alkyl chains, 1,6-anhydro4- $O$-benzyl-2,3-di- $O$-dodecyl- $\beta$-D-mannopyranose (ABDDM) was synthesized by regioselective protection, and polymerized in cationic conditions, giving stereoregular $(1 \rightarrow 6)-\alpha$-D-mannopyranan derivative. Copolymerization of ABDDM with 1,6-anhydro-2,3,4-tri- $O$-benzyl- $\beta$-D-glucopyranose (ATBG) was carried out, and monomer reactivity ratios were calculated by the Kelen-Tüdös method, showing $r_{\mathrm{ABDDM}}=0.51$ and $r_{\mathrm{ATBG}}=0.54$.

KEY WORDS Ring-Opening Polymerization / 2,3-Di-O-alkyl Chains /

Amphiphilic Polysaccharide /
\end{abstract}

Recently, amphiphilic polymers are of great interest in various fields of polymer science, espscially biomaterial science. ${ }^{1,2}$ Some block copolymers, which consist of a hydrophilic block and hydrophobic blocks, are amphiphilic. ${ }^{3}$ Some amphiphilic block copolymers form micelle-like structure, usable as drug carriers for controlled chemical derivery. ${ }^{4}$ Some hydrophilic polymers having hydrophobic groups also form micelle-like structures in aqueous phase. ${ }^{5}$ Recently, Kobayashi et al. designed this type of amphiphilic polysaccharide, i.e., synthetic amphiphilic dextran carrying long alkyl chains at $\mathrm{C}-3$ position. ${ }^{6}$ In this study, we designed $(1 \rightarrow 6)-\alpha$-linked mannopyranan having 2,3-di- $O$-dodecyl residues, because geminal long alkyl chains are similar to lipids in biomembranes. 1,6-Anhydro-4-Obenzyl-2,3-di-O-dodecyl- $\beta$-D-mannopyranose (ABDDM, compound 3) was synthesized and polymerized.

\section{EXPERIMENTAL}

\section{General Methods}

$270-\mathrm{MHz}{ }^{1} \mathrm{H}$ NMR spectra were measured in solution in $\mathrm{CDCl}_{3}$ with tetramethylsilane as internal reference by means of JEOL EX-270 spectrometer. Optical rotations were measured in $\mathrm{CHCl}_{3}$ by means of JASCO LIP1000 diegital polarimeter. Gel-permeation chromatographies were carried out with a Shimadzu LC9A using GPC-802, 803, and 804 columns.

\section{1,6-Anhydro-4-O-benzyl-2,3-O-isopropylidene- $\beta$-D-mannopyranose (1) \\ A solution of 1,6-anhydro-2,3-O-isopropyli-} dene- $\beta$-D-mannopyranose ${ }^{7}(84.6 \mathrm{~g}, 22.8 \mathrm{mmol})$ in $50 \mathrm{ml}$ of $N, N$-dimethylformamide(DMF) was carefully dropped into the vigorously stirred suspention of $\mathrm{NaH}(2.23 \mathrm{~g}, 91.2 \mathrm{mmol})$ in $150 \mathrm{ml}$ of DMF under nitrogen atmosphere at room temperature. After $90 \mathrm{~min}$, benzyl chlo-

\footnotetext{
${ }^{\dagger}$ To whom correspondence should be addressed.
} 
ride $(5.3 \mathrm{ml})$ in $45 \mathrm{ml}$ of DMF was dropped into the reaction mixture taking $30 \mathrm{~min}$, and the mixture was stirred for $21 \mathrm{~h}$. Benzylation was terminated by the careful addition of water. The reaction products were diluted with chloroform, and the organic layer was washed by water and evaporated. 1 was purified by column chromatography using silica gel (hexane : ethyl acetate $=9: 1$ ). Yield $4.45 \mathrm{~g}$, $66.8 \% . \delta_{\mathrm{H}}(\mathrm{ppm}): 1.33$ and $1.53(\mathrm{~s}, 6 \mathrm{H}$, Methyl), 3.68 (s, 1H, H-2), 3.72 (dd, 1H, $J_{5,6}$ $\left.=6.60 \mathrm{~Hz}, J_{6,6^{\prime}}=6,92 \mathrm{~Hz}, \mathrm{H}-6^{\prime}\right), 3.91(\mathrm{dd}$, $1 \mathrm{H}, \mathrm{H} 6), 4.11\left(\mathrm{dd}, 1 \mathrm{H}, J_{3,4}=6.27 \mathrm{~Hz}, J_{4,5}=\right.$ $2.64 \mathrm{~Hz}, \mathrm{H}-4), 4.27$ (d, 1H, H-3), $4.61(\mathrm{~m}, 1 \mathrm{H}$, $\mathrm{H}-5), 4.68\left(\mathrm{~d}, 1 \mathrm{H}, J=12.21 \mathrm{~Hz},-\mathrm{CH}_{2} \mathrm{Ph}\right), 4.72$ (d, $\left.1 \mathrm{H}, J=12.21 \mathrm{~Hz},-\mathrm{CH}_{2} \mathrm{Ph}\right), 5.37(\mathrm{~s}, 1 \mathrm{H}$, $\mathrm{H}-1), 7.37$ (5H, Ph).

\section{1,6-Anhydro-4-O-benzyl- $\beta$-D-mannopyranose}

1 ( $2.40 \mathrm{~g}, 8.22 \mathrm{mmol})$ was dissolved in stirred $80 \%$ trifluoroacetic acid $(50 \mathrm{ml})$ at room temperature. ${ }^{8}$ After $45 \mathrm{~min}$, the water was distilled away in vacuo, and trifluoroacetic acid was removed by azeotropic distillation with toluene. The syrupy residue was chromatographed on silica gel (hexane : ethyl acetate $=2: 3$ ). Yield $1.00 \mathrm{~g}, 48.3 \%$. $\delta_{\mathrm{H}}(\mathrm{ppm}): 3.75(\mathrm{~s}, 1 \mathrm{H}, \mathrm{H}-$ 6), $3.86\left(\mathrm{dd}, 1 \mathrm{H}, \mathrm{H}-6^{\prime}\right), 3.91\left(\mathrm{dd}, 1 \mathrm{H}, J_{3,4}=\right.$ $\left.1.32 \mathrm{~Hz}, J_{4,5}=7.29 \mathrm{~Hz}, \mathrm{H}-4\right), 4.11(\mathrm{dd}, 1 \mathrm{H}$, $\left.J_{1,2}=2.97 \mathrm{~Hz}, J_{2,3}=6.27 \mathrm{~Hz}, \mathrm{H}-2\right), 4.27(\mathrm{~m}$, $1 \mathrm{H}, \mathrm{H}-5), 4.61$ (dd, 1H, H-3), 4.65 (d, 1H, $\left.-\underline{\mathrm{CH}}_{2} \mathrm{Ph}\right), 4.73\left(\mathrm{~d}, 1 \mathrm{H},-\mathrm{C}_{2} \mathrm{Ph}\right), 5.36(\mathrm{~d}, 1 \mathrm{H}$, $\mathrm{H}-1), 7.37$ (5H, Ph).

\section{1,6-Anhydro-4-O-benzyl-2,3-di-O-dodecyl- $\beta$ - D-mannopyranose (ABDDM) (3)}

$2(1.66 \mathrm{~g}, 6.59 \mathrm{mmol})$ was dissolved in a vigorously stirred suspention of $\mathrm{NaH}(0.97 \mathrm{~g}$, $39.5 \mathrm{mmol}$ ) in $70 \mathrm{ml}$ of DMF under nitrogen atmosphere at room temperature. The reaction mixture was stirred for $30 \mathrm{~min}$ at $60^{\circ} \mathrm{C}$. After dropping dodecyl bromide $(5.0 \mathrm{ml}, 5.2 \mathrm{mmol})$, the mixture was stirred for $2 \mathrm{~h}$ at $90^{\circ} \mathrm{C}$. The dodecylation was stopped by adding water and the mixture was diluted by chloroform. The organic layer was washed with water, dried on sodium sulfate, and evapolated to dryness. After purification by column chromatography on silica gel (hexane : ethyl acetate $=9: 2$ ), ABDDM was crystallized from ethanol. Further purification of ABDDM was achieved by column chromatography on silica gel (chloroform as an eluent). Yield $1.94 \mathrm{~g}, 50.1 \%$. $[\alpha]_{\mathrm{D}}^{14.7}=-1.61^{\circ}\left(c 1.0, \mathrm{CHCl}_{3}\right), \delta_{\mathrm{H}}(\mathrm{ppm}): 0.88$ (s, 6H, Methyl), 0.86-1.63 (40H, Methylene), $3.42-3.46\left(6 \mathrm{H}, \mathrm{H}-2, \mathrm{H}-3\right.$, and $\left.-\mathrm{OC}_{2} \mathrm{Alkyl}\right)$, $3.69(\mathrm{~m}, 2 \mathrm{H}, \mathrm{H}-6$ and H-6 $), 4.16(\mathrm{~d}, 1 \mathrm{H}, \mathrm{H}-4)$, $4.49(\mathrm{~m}, 1 \mathrm{H}, \mathrm{H}-5), 4.64\left(\mathrm{~d}, 1 \mathrm{H},-\mathrm{C}_{2} \mathrm{Ph}\right)$, $4.71\left(\mathrm{~d}, 1 \mathrm{H},-\mathrm{CH}_{2} \mathrm{Ph}\right), 5.44(\mathrm{~s}, 1 \mathrm{H}, \mathrm{H}-1), 7.36$ $(5 \mathrm{H}, \mathrm{Ph}$ ), elemental analysis (Calcd: $\mathrm{C}, 75.46 \%$; $\mathrm{H}, 10.95 \%$. Found: C, 74.69\%; H, 11.31\%), mp $66-67^{\circ} \mathrm{C}$.

\section{Polymerization and Copolymerizations}

Ring-opening polymerization of ABDDM was carried out under cationic conditions using phosphorous pentafluoride as the initiator under high vacuum. ${ }^{9}$ The polymerization was terminated by the addition of methanol. Purification of the polymer was performed by three times dissolution-reprecipitation using chloroform-methanol system. Finally, the polymer was freeze-dried from benzene solution. Average molecular weights were determined by gel-permeation chromatography using polystyrenes as standards. Stereoregularities of the polymers were confirmed from ${ }^{13} \mathrm{C}$ NMR spectra.

As shown in Tables II and III, copolymerizations of ABDDM with 1,6-anhydro-2,3,4tri- $O$-benzyl- $\beta$-D-glucopyranose(ATBG) or 1,6anhydro-2,3,4-tri- $O$-benzyl- $\beta$-D-mannopyranose (ATBM) were carried out at various ratios in the feed. The copolymerizations were conducted according to the same method of the ring-opening polymerization of ABDDM.

\section{RESULTS AND DISCUSSION}

Synthesis of ABDDM

ABDDM was synthesized from 1,6-anhy- 
dro-2,3- $O$-isopropyridene- $\beta$-D-mannopyranose by three steps as shown in Scheme 1. 1,6-Anhydro-4- $O$-benzyl- $\beta$-D-mannopyranose (2) was synthesized according to a modification of the method of Reeves. ${ }^{10} 2$ was synthesized also by benzylidenation of 1,6 -anhydro- $\beta$-Dmannopyranose followed by benzylation and removal of benzylidene group. However, the total yield was much less than the synthetic route using isopropylidene group. Dodecylation of $\mathbf{2}$ gave ABDDM of which the structure was confirmed by ${ }^{1} \mathrm{H}$ NMR spectroscopy.

\section{Ring-Opening Polymerization of ABDDM}

Generally, 1,6-anhydro- $\beta$-D-mannopyranose derivatives have relatively high polymerizabilities compared with other 1,6-anhydro-hexsose derivatives. ${ }^{11,12}$ ABDDM was no exception to this rule. Polymerizations of

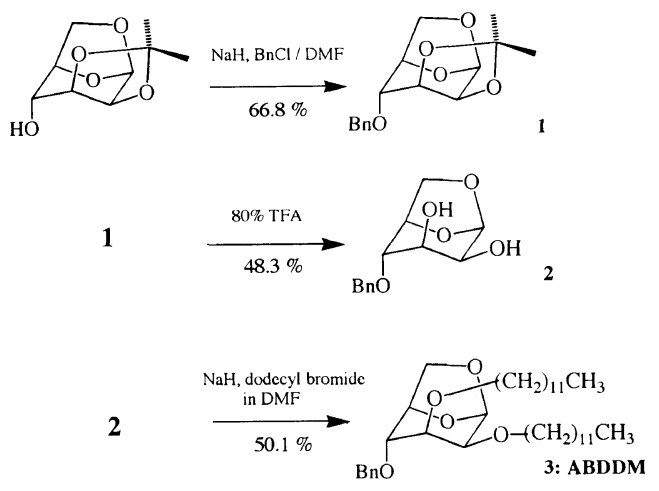

Scheme 1. Synthesis of ABDDM.
ABDDM were carried out at $-40^{\circ} \mathrm{C}$. The results of polymerization of ABDDM are summarized in Table I. Number average molecular weights of the polymers were from 4000 to $21000 .{ }^{13} \mathrm{C}$ NMR spectra of the obtained polymers showed single $\mathrm{Cl}$ peak at $98.76 \mathrm{ppm}$ (Figure 1), indicating that the polymers have stereoregular structures. The specific rotation of the polymers was as high positive as that of stereoregular 2,3,4-tri-O benzyl-( $1 \rightarrow 6)-\alpha$-D-mannopyranan. ${ }^{13}$ It was concluded that the obtained polysaccharide derivatives were stereoregular 4- $O$-benzyl-2,3di-O-dodecyl-( $1 \rightarrow 6)$ - $\alpha$-D-mannopyranans (4) (Scheme 2). Polymer 4 has regioselectively oriented dodecyl groups at C-2 and C-3, which constitute the hydrophobic domain directed to the same side of the plane of the pyranose ring (Scheme 3). Consequently, 4 may be a key material for making various functional amphiphilic polymers, if 4-O-benzyl group can be removed and the hydroxyl group at C-4 can be modified with hydrophilic group such as glycosyl branch.

\section{Copolymerization of $A B D D M$ with $A T B G$ or ATBM}

The results of copolymerization of ABDDM with ATBG are summarized in Table II. The mole fractions of ABDDM units in copolymers were determined by ${ }^{1} \mathrm{H}$ NMR spectroscopy. The signals at $3.0-5.1 \mathrm{ppm}$ are due to the pyranose ring protons, metylene protons of

Table I. Ring-opening polymerization of $\mathrm{ABDDM}^{\mathrm{a}}$

\begin{tabular}{|c|c|c|c|c|c|c|c|c|c|}
\hline No. & $\begin{array}{c}\text { Concn } \\
\mathrm{moll}^{-1}\end{array}$ & $\frac{\mathrm{PF}_{5}}{\operatorname{mol} \%}$ & $\frac{\text { Time }}{\mathrm{h}}$ & $\begin{array}{c}\text { Yield } \\
\%\end{array}$ & {$[\alpha]_{\mathrm{D}}^{25}$} & $\begin{array}{c}\bar{M}_{n}^{\mathrm{c}} \\
\times 10^{-4}\end{array}$ & $\begin{array}{c}\bar{M}_{w}{ }^{\mathrm{c}} \\
\times 10^{-4}\end{array}$ & $\bar{M}_{w} / \bar{M}_{n}$ & $\overline{D P}_{n}$ \\
\hline 1 & 0.34 & 4 & 72 & 4.5 & N.D. & 0.40 & 0.43 & 1.1 & 6.79 \\
\hline 2 & 0.34 & 5 & 73 & 6.1 & N.D. & 1.0 & 1.7 & 1.7 & 17.0 \\
\hline 3 & 0.34 & 10 & 76 & 43.0 & +61 & 2.1 & 4.3 & 2.1 & 35.7 \\
\hline 4 & $0.68^{\mathrm{b}}$ & 10 & 34 & 26.0 & N.D. & 0.72 & 1.4 & 1.9 . & 12.2 \\
\hline 5 & 0.17 & 20 & 12 & 25.0 & +53 & 1.2 & 2.2 & 1.8 & 20.4 \\
\hline
\end{tabular}

${ }^{\text {a }}$ Monomer, $200 \mathrm{mg}$; solvent, $\mathrm{CH}_{2} \mathrm{Cl}_{2}$; temp, $-40^{\circ} \mathrm{C}$. ${ }^{b}$ Solvent, toluene. ${ }^{\mathrm{c}}$ Determined by GPC using polystyrene standards. 


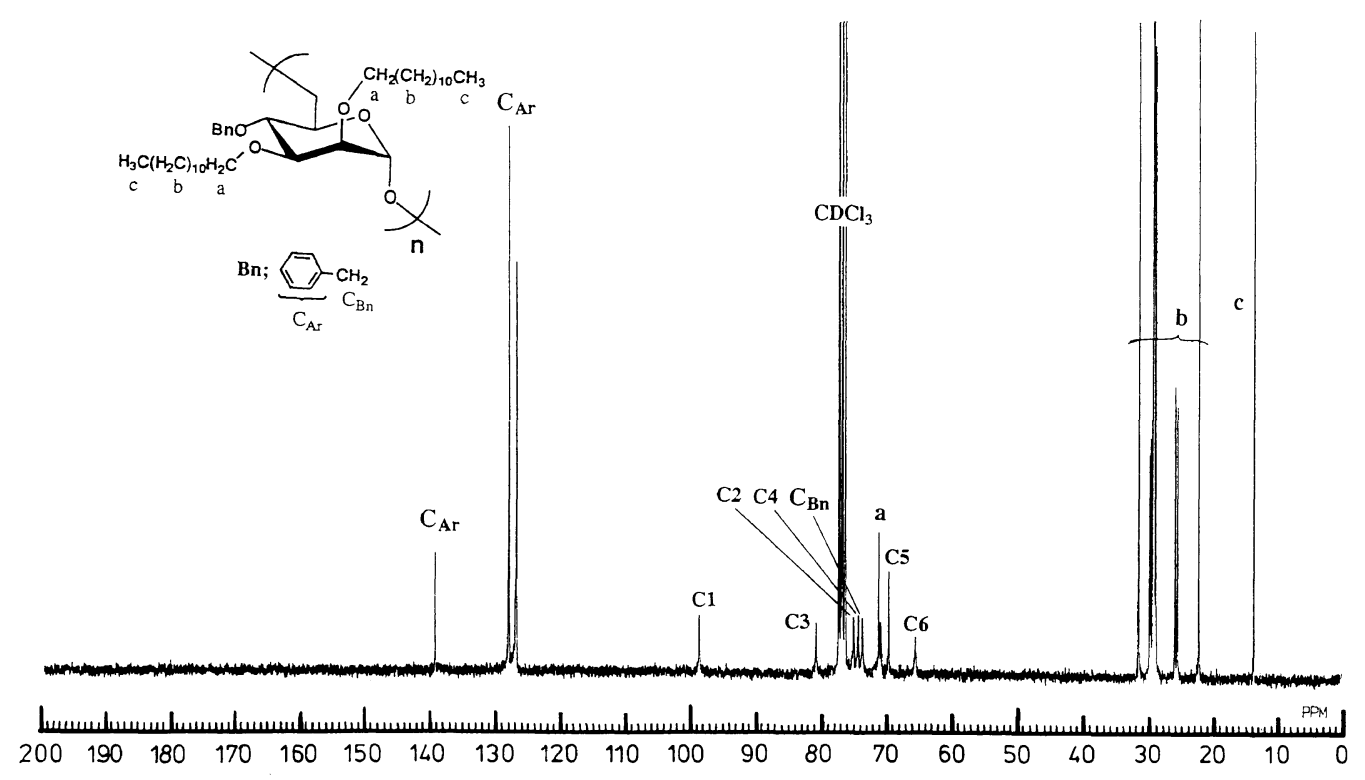

Figure 1. ${ }^{13} \mathrm{C}$ NMR spectrum of 4 - $O$-benzyl-2,3-di- $O$-dodecyl $(1 \rightarrow 6)$ - $\alpha$-D-mannopyranan (No. 3 in Table I).

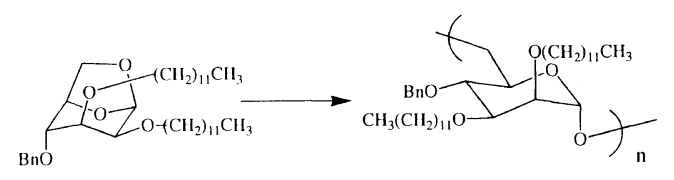

Scheme 2. Ring-opening polymerization of ABDDM.

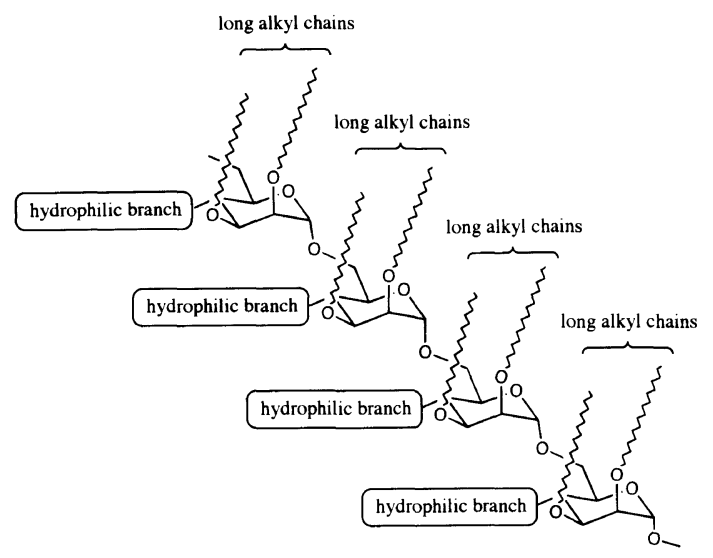

Scheme 3. Simplified model of amphiphilic polysaccharide derived from poly(ABDDM) as a key material. benzyl groups, and $O$-linked methylene protons of dodecyl groups. Absorptions at $0.8-1.6 \mathrm{ppm}$ are assignable to C-linked methylene and methyl groups of dodecyl residues. Accordingly, the fraction of ABDDM units was calculated by using the relative intensities of the absorptions in the two regions. In each case, the mole fraction of ABDDM units in the copolymer was higher than that in the initial monomer feed, indicating that ABDDM was efficiently taken into the copolymer (Table II). Monomer reactivity ratios were calculated as $r_{\mathrm{ABDDM}}=0.51$ and $r_{\text {ATBG }}=0.54$ by using the Kelen-Tüdös method. ${ }^{14} r_{\mathrm{ATBG}}=0.54$ indicates higher reactivity of ABDDM monomer to the active cation derived from ATBG than the ATBG monomer. Although ATBG is a monomer with high reactivity in many copolymerizations, the reactivity of the ABDDM was higher than ATBG. $r_{\mathrm{ABDDM}}=0.51$ showed low reactivity of ABDDM monomer to the active cation derived from ABDDM. ABDDM has bulky long alkyl chains at C-2 and C-3. Therefore, 
Polysaccharides Carrying 2,3-Di- $O$-alkyl Chains

Table II. Copolymerization of ABDDM with $\mathrm{ATBG}^{\mathrm{a}}$

\begin{tabular}{|c|c|c|c|c|c|c|c|c|c|}
\hline \multirow{2}{*}{ No. } & $\begin{array}{l}\text { ABDDM } \\
\text { in feed }\end{array}$ & $\begin{array}{l}\text { ATBG } \\
\text { in feed }\end{array}$ & \multirow{2}{*}{$\begin{array}{l}\text { Mol fraction } \\
\text { of ABDDM } \\
\text { in feed }\end{array}$} & \multirow{2}{*}{$\frac{\text { Time }}{\mathrm{h}}$} & \multirow{2}{*}{$\frac{\text { Yield }}{\%}$} & \multirow{2}{*}{$\begin{array}{l}\text { Mol fraction } \\
\text { of ABDDM } \\
\text { in copolymer }\end{array}$} & \multirow{2}{*}{$\begin{array}{c}\bar{M}_{n}^{\mathrm{b}} \\
\times 10^{-4}\end{array}$} & \multirow{2}{*}{$\begin{array}{c}\bar{M}_{w}{ }^{\mathrm{b}} \\
\times 10^{-4}\end{array}$} & \multirow{2}{*}{$\bar{M}_{w} / \bar{M}_{n}$} \\
\hline & $\mathrm{g}$ & $\mathrm{g}$ & & & & & & & \\
\hline 1 & 0.06 & 0.43 & 0.09 & 4.5 & 12.0 & 0.15 & 3.9 & 6.5 & 1.7 \\
\hline 2 & 0.09 & 0.20 & 0.26 & 3.5 & 6.2 & 0.37 & 0.72 & 1.1 & 1.5 \\
\hline 3 & 0.09 & 0.125 & 0.50 & 48.0 & 35.0 & 0.57 & 4.6 & 11.0 & 2.5 \\
\hline 4 & 0.34 & 0.027 & 0.90 & 3.5 & 5.5 & 0.93 & N.D. & N.D. & N.D. \\
\hline
\end{tabular}

${ }^{a}$ Initiator, phosphorous pentafluoride; solvent, $\mathrm{CH}_{2} \mathrm{Cl}_{2}$, temp, $-40^{\circ} \mathrm{C}$. ${ }^{\mathrm{b}}$ Determined by $\mathrm{GPC}$ using polystyrene standards.

Table III. Copolymerization of ABDDM with ATBM ${ }^{a}$

\begin{tabular}{|c|c|c|c|c|c|c|c|c|c|}
\hline \multirow{2}{*}{ No. } & $\begin{array}{l}\text { ABDDM } \\
\text { in feed }\end{array}$ & $\begin{array}{l}\text { ATBM } \\
\text { in feed }\end{array}$ & \multirow{2}{*}{$\begin{array}{l}\text { Mol fraction } \\
\text { of ABDDM } \\
\text { in feed }\end{array}$} & \multirow{2}{*}{$\frac{\text { Time }}{\mathrm{h}}$} & \multirow{2}{*}{$\frac{\text { Yield }}{\%}$} & \multirow{2}{*}{$\begin{array}{l}\text { Mol fraction } \\
\text { of ABDDM } \\
\text { in copolymer }\end{array}$} & \multirow{2}{*}{$\begin{array}{c}\bar{M}_{n}{ }^{\mathrm{b}} \\
\times 10^{-4}\end{array}$} & \multirow{2}{*}{$\begin{array}{c}\bar{M}_{w}^{b} \\
\times 10^{-4}\end{array}$} & \multirow{2}{*}{$\bar{M}_{w} / \bar{M}_{n}$} \\
\hline & $\mathrm{g}$ & g & & & & & & & \\
\hline 1 & 0.030 & 0.125 & 0.05 & 80 & 5.4 & 0.46 & 5.4 & 13 & 2.4 \\
\hline 2 & 0.180 & 0.400 & 0.25 & 30 & $<0.1$ & 0.40 & 1.9 & 3.2 & 1.7 \\
\hline 3 & 0.090 & 0.125 & 0.50 & 67 & 20.0 & 0.59 & 1.0 & 1.6 & 1.6 \\
\hline
\end{tabular}

${ }^{\mathrm{a}}$ Initiator, phosphorous pentafluoride; solvent, $\mathrm{CH}_{2} \mathrm{Cl}_{2}$; temp, $-40^{\circ} \mathrm{C}$. ${ }^{\mathrm{b}}$ Determined by $\mathrm{GPC}$ using polystyrene standards.

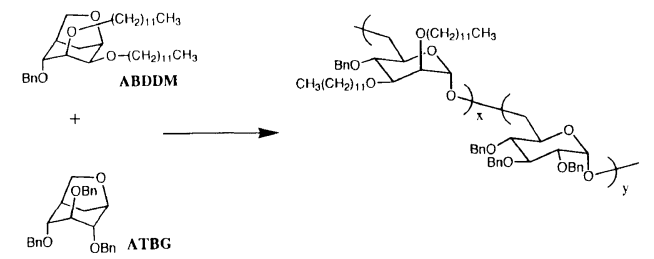

Scheme 4. Copolymerization of ABDDM and ATBG.

these dodecyl groups may cause steric hindrance between the ABDDM monomer and the ABDDM-derived cation.

Copolymerizations of ABDDM with 1,6anhydro-2,3,4,-tri- $O$-benzyl- $\beta$-D-mannopyranose (ATBM), were also done. ABDDM units were efficiently taken into copolymers as well as the copolymerization with ATBG, indicating that ABDDM must have high polymerizability, because ATBM is the most reactive monomer among tri- $O$-benzylated 1,6-anhydro-hexoses. In this journal, we reported the effects of electron-withdrawing groups at $\mathrm{C}-2$ position of 1,6-anhydro- $\beta$-D-mannopyranose deriva- tives on polymerizability. ${ }^{15}$ It was suggested that the electron-withdrawing groups at C-2 position of 1,6 -anhydro- $\beta$-D-mannopyranose derivatives decrease the electron density of 1,6-anhydro oxygen. ABDDM has an electrondonating group at $\mathrm{C}-2$ position. The absorption of $\mathrm{H}-1$ proton of ABDDM whose chemical shift was $5.44 \mathrm{ppm}$, appeared at a similar magnetic field of $\mathrm{H}-1$ proton of ATBM $(5.45 \mathrm{ppm})$. Therefore, it was indicated that the electron density of 1,6-anhydro oxygen of ABDDM may be as high as ATBM. In other words, ABDDM may be a high reactive monomer as well as ATBM because of the electron-donating group at C-2 position of ABDDM. That is to say, the polymerization of ABDDM and copolymerization with other 1,6-anhydro-hexose monomers can give polysaccharide derivatives carrying the hydrophobic domain. Debenzylation of copolymers of ABDDM with 1,6-anhydro-hexoses may introduce hydrophobic and hydrophilic regions into copolymers without any modifications. 


\section{REFERENCES}

1. S. Tobe, Y. Takei, K. Kobayashi, and T. Akaike, Biochem. Biophys. Res. Commun., 184, 225 (1992).

2. M. Yokoyama, G. S. Kwon, T. Okano, Y. Sakurai, T. Seto, and K. Kataoka, Bioconj. Chem., 3, 295 (1992).

3. M. Wilhem, C. Zhao, Y. Wang, R. Xu, M. A. Winnik, J. Mura, G. Riess, and M. D. Croucher, Macromolecules, 24, 1033 (1991).

4. M. Yokoyama, T. Okano, Y. Sakurai, H. Ekimoto, C. Shibazaki, and K. Kataoka, Cancer Res., 51, 3229 (1991).

5. M. Goto, A. Kobayashi, K. Kobayashi, K. Saito, and T. Akaike, Chem. Lett., 123 (1992).

6. K. Kobayashi, H. Ichikawa, and H. Sumitomo, Macromolecules, 23, 3708 (1990).
7. M. Georges and B. Fraser-Reid, Carbohydr. Res., 127, 162 (1984).

8. R. van Rijsbergen, M. J. O. Anteunis, and A. D. Bruyn, J. Carbohydr. Chem., 2, 395 (1983).

9. T. Uryu, M. Yamanaka, M. Henmi, K. Hatanaka, and K. Matsuzaki, Carbohydr. Res., 157, 157 (1986).

10. R. E. Reeves, J. Am. Chem. Soc., 71, 2116 (1949).

11. C. Schuerch, Adv. Carbohydr. Chem. Biochem., 39, 157 (1981).

12. N. K. Kochetkov, Tetrahedron, 43, 2389 (1987).

13. J. Frechet and C. Schuerch, J. Am. Chem. Soc., 91, 1161 (1969).

14. T. Kelen and F. Tüdös, J. Macromol. Sci. Chem., A9, 1 (1975).

15. K.-I. Kanno, Y. Kobayashi, and K. Hatanaka, Polym. J., 27, 71 (1995). 